\title{
Kinematic analysis of symmetric axial trunk rotation on dominant hip
}

\author{
Paul S. Sung, PhD, DHSc, PT; ${ }^{\text {** }}$ Yoon Hyuk Kim, PhD $^{\mathbf{2}}$ \\ ${ }^{1}$ Department of Physical Therapy, College of Health Science, Korea University, Seoul, Korea; ${ }^{2}$ Department of \\ Mechanical Engineering, School of Engineering, Kyung Hee University, Yongin, Korea
}

\begin{abstract}
Axial rotation of the trunk has been reported as a significant risk of low back dysfunction. However, a lack of biomechanical investigation exists that explains how twisting is accomplished with simultaneous asymmetric handling between the hip joints and lumbar spine. We used a threedimensional motion analysis to measure movements of the bilateral hips and lumbar spine. Forty-four persons participated in the study, and the results indicated that spinal range of motion (ROM) was significantly different based on dominance $(F=198.83, p=0.001)$, region $\mathrm{x}$ dominance $(F=14.21, p=$ $0.001)$, and dominance $\mathrm{x}$ dimension $(F=141.08, p=0.001)$. We also found a three-way interaction between region $\mathrm{x}$ dominance $\mathrm{x}$ dimension $(F=26.30, p=0.001)$. These results indicated that the motion of the transverse and sagittal planes significantly increased when the participants attempted to rotate their hips, especially on the nondominant side. Decreased axial trunk ROM on the side of dominance might stiffen passive structures of the hip joints. The functions of the hip joints and lumbar spine might be altered three dimensionally based on the side of dominance.
\end{abstract}

Key words: axial rotation, biomechanics, dominance, hip, kinematic changes, motion analysis, range of motion, rehabilitation, spinal inflexibility, trunk.

\section{INTRODUCTION}

Axial twisting of the torso has been identified as a significant risk of low back pain (LBP), which is the most common type of musculoskeletal degeneration in our society [1-3]. The coordination of trunk motion during functional movements depends on flexibility and stability of the hips, with optimal range of motion (ROM) within the whole spine [4-6].

A high correlation exists between hip motion and total axial rotation, thus suggesting that improving flexibility of the hips would alleviate pain and its recurrent episodes [7]. Postural control might require a more complex process involving integrated motor function for impaired balance performance in participants with LBP [8-9]. For example, participants with LBP who have radiating leg pain demonstrated limited movement during physiological movements of the hip and lumbar spine [10]. Other investigators also reported decreased trunk flexibility and low back muscle stiffness in participants with LBP [11-14]. As a result, investigating muscular control in and around the trunk and hip joints is important in developing rehabilitation strategies for preventing back injury [15-18].

Previously, our laboratory reported that investigators should methodologically consider hand dominance for back pain research [19]. In lieu of this dominance, failing to consider the lower-limb dominance explicitly along

Abbreviations: $3-\mathrm{D}=$ three-dimensional, $\mathrm{ANOVA}=$ analysis of variance, $\mathrm{LBP}=$ low back pain, $\mathrm{ROM}=$ range of motion.

*Address all correspondence to Paul S. Sung, PhD, DHSc, PT; Department of Physical Therapy, Korea University, 1 Jeongneung 3-dong, Sungbuk-gu, Seoul, Korea 136-703; +82-2-940-2830; fax: +82-2-940-2830.

Email: psung@korea.ac.kr

DOI:10.1682/JRRD.2010.12.0232 
with the side assessed may confound results for muscleactivity-related outcomes. However, a lack of kinematic analysis exists for postural alignment with a specific spine model, which has not been comprehensively investigated between the hip joints and lumbar spine with neuromuscular functional activities.

Therefore, quantifying three-dimensional (3-D) changes is necessary in angular displacement of the hip joints by motion analysis with a biomechanical spine model in participants with LBP. Since several factors are related to motion changes of the hip joints, effects of dominant side should be investigated while the whole spine during trunk axial rotation is considered. Maintaining stability and normal function of the spine is crucial under static and dynamic conditions. Axial rotation of the trunk with simultaneous loads may be a significant risk of low back injuries [20-21]. The deficits could include spinal inflexibility, different compensatory strategies of the hip joints, and abnormal patterns of postural responses. However, lack of a comprehensive examination of postural alignment exists between the whole spine and hip joints based on 3-D kinematic changes.

In our study, we investigated overall kinematic changes while considering anthropometric factors such as age, height, and body weight. Therefore, this study compared the effects of the dominance of 3-D kinematic changes on the lumbar spine and hip joints from the axis of the core spine in nondisabled participants during axial rotation activities while standing.

\section{METHODS}

\section{Participants}

Participants were volunteers from a health promotion club in Seoul, Korea, and we contacted them to minimize the risk of confounding effects and to increase internal validity of the data [22]. Those volunteers who met study inclusionary criteria received information regarding the purpose and methods of the study before signing a copy of the institutional review board approved consent form.

Volunteers for this study were participants without LBP who did not experience a disturbing impairment or abnormality in the functioning of the low back during the previous 2 months. Volunteers were included in this study if they (1) were 18 years of age or older, (2) did not experience LBP or pain referral in the lower limbs, (3) reported no symptoms of back or hip pain during axial trunk rotation activities, and (4) were right-limb dominant [23]. Volunteers were excluded from participating if they (1) had a diagnosed psychological illness that might interfere with the study protocol, (2) had overt neurological signs (sensory deficits or motor paralysis), and/or (3) were pregnant. Participants were withdrawn from the study if they requested to withdraw [22]. All participants completed a survey and questionnaire that included health information regarding anthropometric factors such as age, height, and weight.

\section{Outcome Measures}

The axial trunk rotation test was standardized so that the examiner could accurately measure all the participants. The participants performed five trials in which they were instructed to stand quietly upright with their eyes open and hips and knees fully extended, with both feet shoulder width apart. Participants rotated their trunks in the transverse plane (right and left axial rotation) as they twisted their trunks to both sides while holding a stick bar at the height of their shoulders.

The participants stood upright on a force plate surface and performed five trials of the trunk rotation test at a self-selected speed $(0.8 \pm 0.2 \mathrm{~m} / \mathrm{s})$. The trunk rotation included voluntary exertions in which participants turned in the counterclockwise and clockwise directions. The participants were instructed to turn their shoulders, hips, and knees without moving their feet. They were given disposable hospital slipper socks to wear during the test and had the Helen Hayes full-body (with head) reflective marker set attached to specific sites on their bodies with adhesive tape rings [22-23].

In Figure 1, we calculated the core spine axis based on the coordinates between the center of the pelvic and shoulder planes. The lumbar spine is the line between the center of the second sacrum and the twelfth thoracic spine levels [22]. The 3-D planes included the anteriorposterior (frontal), mediolateral (sagittal), and vertical (transverse) axes from the core spine axis and were calculated during trunk axial rotation. We calculated the average angular data for five complete trunk axial rotations (counterclockwise followed by clockwise) during the isolated trunk rotation task.

We recorded and processed synchronized kinematic data of joint angles using six digital cameras, capturing 3-D full-body kinematic motion sampling (Motion Analysis Corporation; Santa Rosa, California) at $120 \mathrm{~Hz}$. All kinematic data of joint angles were time-synchronized within 
(a)

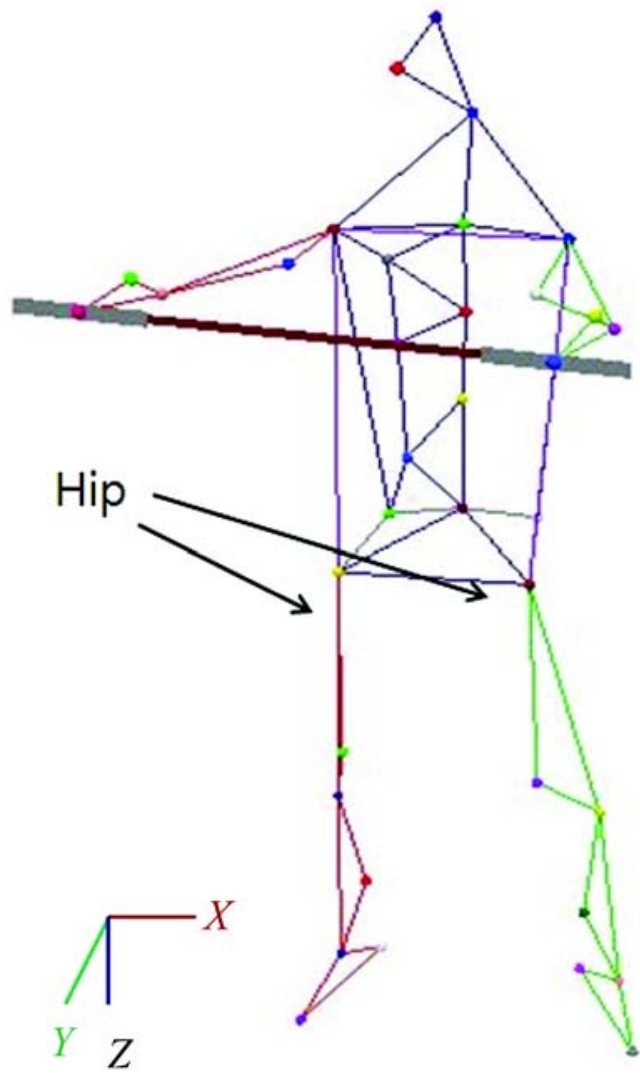

(b)

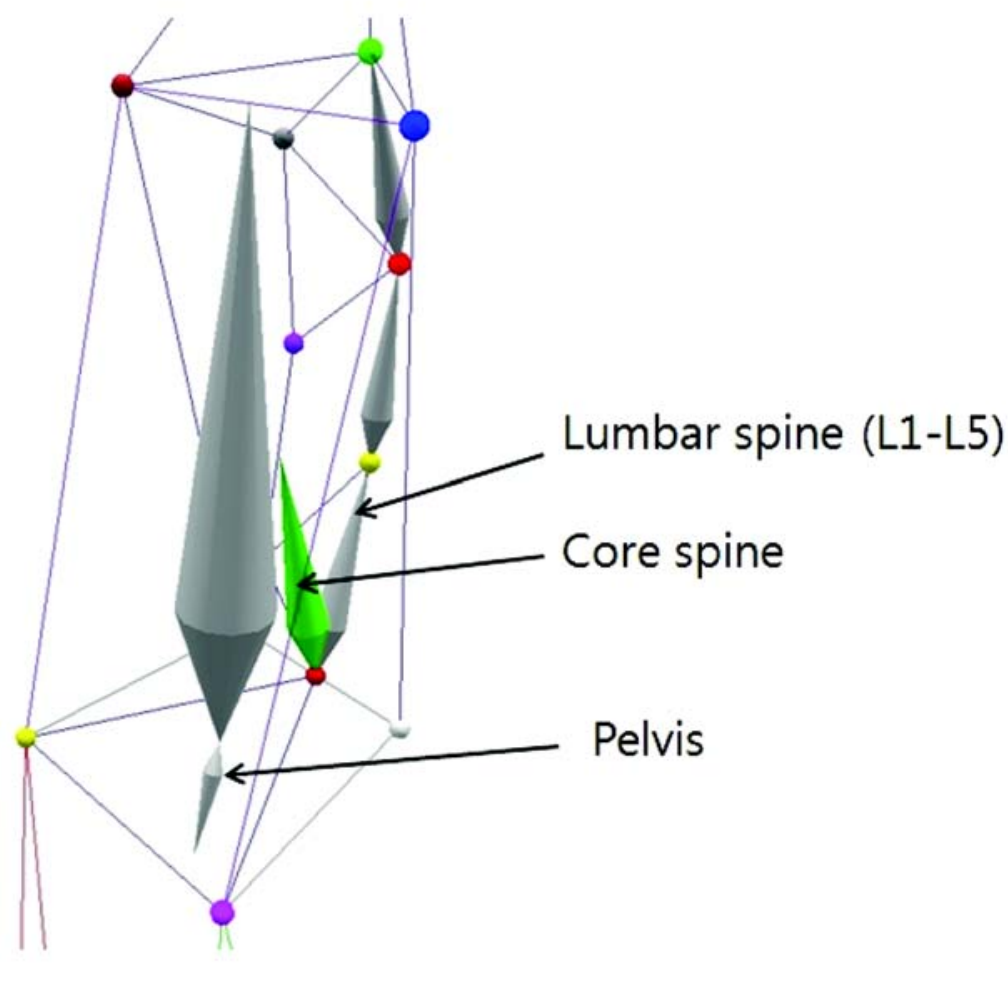

Figure 1.

Axial rotation test in standing position. (a) Participant stands with both legs fully extended with stick bar and performs axial rotation activities five times repeatedly. During testing, (b) participants maintain standing stability while reflective markers collect kinematic data from three spine axes ( $X=$ frontal, $Y=$ sagittal, $Z=$ transverse planes). L1-L5 = lumbar vertebrae 1-5.

the test cycle. In addition, we collected and tracked digital video data using EVA 5.20 (Motion Analysis Corporation) and then imported the data into Orthotrac 5.2 (Motion Analysis Corporation) [22-23].

The body segments were modeled as rigid bodies, and the relative rotation angle was taken from a fixed point in the center of the joint. We applied the kinematic angles to describe relative rotations of one segment with respect to another reference segment. Therefore, we derived lumbar spine angles from the relative orientation based on the core spine axis. The hip joint angle was taken from the hip and sacral sensors on the basis of the core spine axis. The method of computation was based on mathematical techniques, and kinematic joint angles were derived from the direction cosine matrixes of the sensors [24-25]. We measured maximum angle based on the direction of the rotation, which was either counterclockwise or clockwise at $70^{\circ}$. Therefore, the maximum values were actually the average angle of the five repeated trunk rotations to each direction.

We also applied participant handedness in this study since the previous study confirmed that handedness could be a confounding factor for a back muscle study [19]. In addition, in the current study, we regarded the right lower limb as the dominant side for all participants because they preferred to use the right limb to kick a ball [26-27].

\section{Statistical Analyses}

We completed statistical analyses using SPSS 16 (SPSS; Chicago, Illinois). Normality was assessed for each of the dependent variables. We used an independent $t$-test to analyze dependent variables based on each group (male and female). We used a repeated measures analysis of variance (ANOVA) for each dependent variable to determine the main effects of each group. To eliminate 
confounding effects, we used the age, height, and weight variables as covariates. We evaluated all continuous dependent variables using the general linear model [28]. For all statistical analyses, type I error rate was set at 0.05 .

\section{RESULTS}

\section{Participants}

In total, 44 persons participated in the study, including 28 females and 16 males. The average age of the participants was $40.8 \pm 18.2$ years and ranged from 21 to 72 years. The female group was slightly younger (39.7 \pm 18.7) than the male group $(43.1 \pm 17.4)$, but no significant difference existed between groups $\left(\chi^{2}=28.13, p=\right.$ $0.30)$. The male participants were slightly taller (172.5 \pm $6.9 \mathrm{~cm})$ than the female participants $(160.8 \pm 5.3 \mathrm{~cm})$, although height was not significantly different between groups $\left(\chi^{2}=27.65, p=0.32\right)$. Weight was not significantly different between groups $\left(\chi^{2}=25.76, p=0.26\right)$.

\section{Sex Differences in Kinematic Displacements}

In Table 1, the average angles for the dominant and nondominant hips as well as the lumbar spine were compared between sexes during axial trunk rotation. Data show that the male group demonstrated decreased angular motion for both hips compared with that of the female group, especially in the transverse axis $(Z)$ of the lumbar spine $\left(15.48^{\circ} \pm 5.21^{\circ}\right.$ vs $\left.11.51^{\circ} \pm 5.07^{\circ}\right)$. This difference was statistically significant between sexes $(t$-value $=2.46$, $p=0.02$ ). However, the other angular motions were not significantly different between sexes.

\section{Group Analysis of Spinal Kinematic Data}

For the effect of group differences on kinematic data during the axial rotation test, Table 2 shows the repeated measures ANOVA that was conducted for comparing the ROM differences of the dominant and nondominant sides of the lumbar spine as well as both hips. The spinal ROM was significantly different between dominance $(F=$ 198.83, $p=0.001)$, region $\times$ dominance $(F=14.21, p=$ $0.001)$, and dominance $\times$ dimension $(F=141.08, p=$ $0.001)$. We found a three-way interaction between region $x$ dominance $\times$ dimension $(F=26.30, p=0.001)$. In Figure 2, 3 -D spinal ROMs for axial trunk rotations were summarized for the dominant and nondominant side differences for the lumbar spine as well as both hip joints.
We found a significant interaction in age, dominance, and dimension ( $F=4.64, p=0.03)$. However, we found no age interactions with region $(F=0.01, p=0.74)$, dominance $(F=0.04, p=0.84)$, or region $\times$ dominance $(F=$ $0.02, p=0.89$ ). In addition, we found no significant interaction in dominance $\times$ dimension $(F=2.65, p=0.11)$ during axial trunk rotation. Overall, the combined effect of dominance $\times$ dimension demonstrated an interaction with age.

\section{DISCUSSION}

While considering anthropometric factors, this study compared the side effects of dominance of 3-D kinematic changes on the hip joints and lumbar spine from the axis of the core spine during axial rotation activities in participants while standing. Recent studies indicated that postural chain mobility might be necessary for spinal

\section{Table 1.}

Kinematic angular displacement $\left(^{\circ}\right)$ for each spinal region and plane $(X, Y$, and $Z$ ) of dominant and nondominant sides during axial rotation test of male $(n=16)$ and female groups $(n=28)$.

\begin{tabular}{lcccc}
\hline Side & $\begin{array}{c}\text { Female } \\
\text { (Mean } \pm \text { SD) }\end{array}$ & $\begin{array}{c}\text { Male } \\
\text { (Mean } \pm \text { SD) }\end{array}$ & t-Value & p-Value \\
\hline Dominant & & & & \\
Lumbar $X$ & $15.29 \pm 6.30$ & $13.49 \pm 5.41$ & 0.98 & 0.32 \\
Lumbar $Y$ & $5.65 \pm 3.24$ & $4.83 \pm 2.46$ & 0.93 & 0.36 \\
Lumbar $Z$ & $15.48 \pm 5.21$ & $11.51 \pm 5.07$ & 2.46 & $0.02^{*}$ \\
L Hip $X$ & $13.31 \pm 6.76$ & $12.89 \pm 6.56$ & 0.20 & 0.84 \\
L Hip $Y$ & $7.93 \pm 4.86$ & $7.87 \pm 4.01$ & 0.04 & 0.96 \\
L Hip $Z$ & $49.42 \pm 9.36$ & $48.19 \pm 10.11$ & 0.39 & 0.69 \\
R Hip $X$ & $10.50 \pm 5.92$ & $10.76 \pm 5.12$ & -0.15 & 0.89 \\
R Hip $Y$ & $12.76 \pm 5.50$ & $12.40 \pm 5.26$ & 0.21 & 0.83 \\
R Hip $Z$ & $48.85 \pm 10.11$ & $51.78 \pm 10.13$ & -0.91 & 0.36 \\
Nondominant & & & & \\
Lumbar $X$ & $16.85 \pm 4.29$ & $14.34 \pm 3.96$ & -1.95 & 0.06 \\
Lumbar $Y$ & $7.12 \pm 4.71$ & $5.46 \pm 3.65$ & -1.29 & 0.20 \\
Lumbar $Z$ & $10.76 \pm 4.03$ & $11.34 \pm 6.05$ & -1.29 & 0.73 \\
L Hip $X$ & $11.97 \pm 6.03$ & $9.95 \pm 6.15$ & -1.06 & 0.29 \\
L Hip $Y$ & $14.11 \pm 5.98$ & $14.13 \pm 4.65$ & -0.02 & 0.98 \\
L Hip $Z$ & $45.89 \pm 8.36$ & $48.79 \pm 13.28$ & -0.79 & 0.43 \\
R Hip $X$ & $8.03 \pm 4.80$ & $7.30 \pm 5.11$ & -0.46 & 0.64 \\
R Hip $Y$ & $10.16 \pm 4.80$ & $7.30 \pm 5.10$ & 0.41 & 0.68 \\
R Hip $Z$ & $55.89 \pm 21.20$ & $44.98 \pm 13.66$ & -1.55 & 0.12 \\
\hline * $<$ < 0.05. & & & & \\
L = left, R right, SD standard deviation. & & & \\
\hline \hline
\end{tabular}


Table 2.

Results of repeated measures analysis of variance for each spinal region (lumbar and right and left hip joints) and plane ( $X, Y$, and $Z$ ).

\begin{tabular}{lrrl}
\hline \multicolumn{1}{c}{ Effect } & $\begin{array}{c}\text { Mean } \\
\text { Square }\end{array}$ & F-Value & $\boldsymbol{p}$-Value \\
\hline Region & 55.52 & 0.72 & 0.40 \\
Dominance & $21,153.28$ & 198.83 & $0.001^{*}$ \\
Region $\times$ Dominance & $1,019.19$ & 14.21 & $0.001^{*}$ \\
Region $\times$ Dimension & 306.35 & 3.12 & 0.08 \\
Dominance $\times$ Dimension & $8,646.72$ & 141.08 & $0.001^{*}$ \\
Region $\times$ Dominance $\times$ & $2,475.38$ & 26.30 & $0.001^{*}$ \\
$\quad$ & & \\
Dimension & & \\
$p<0.01$. &
\end{tabular}

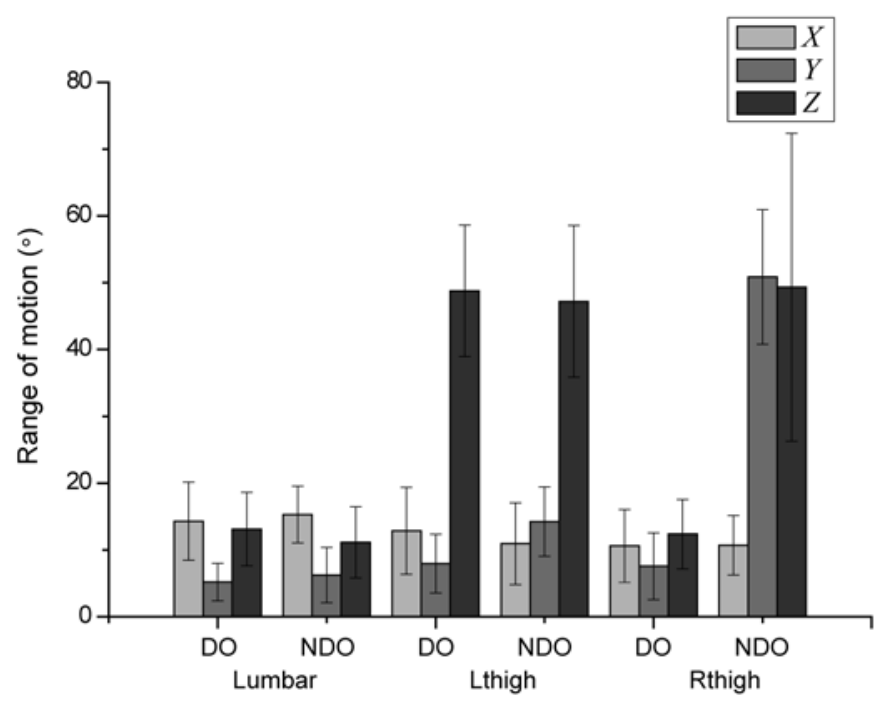

Figure 2.

Three-dimensional spinal range of motion (ROM) differences for axial rotation to dominant (DO) and nondominant (NDO) directions. Spinal ROM was significantly different between dominance $(F=198.83, p=$ $0.001)$, region $\times$ dominance $(F=14.21, p=0.001)$, and dominance $\times$ dimension $(F=141.08, p=0.001)$. A three-way interaction was found between region, dominance, and dimension $(F=26.30, p=0.001)(X=$ frontal, $Y=$ sagittal, $Z=$ transverse planes). Error bars indicate standard deviation from mean. $\mathrm{L}=$ left, $\mathrm{R}=$ right.

stability in the pelvic and lumbar spine regions as well as the hip joints [29-31]. For example, participants with LBP were able to manage the lifting activity by increasing lumbar and hip movements in the frontal and horizontal planes of motion while limiting movements in the sagittal plane [31]. However, no specific kinematic measure existed for the differences between the lumbar spine and hips during axial trunk rotation while the lower-limb side of dominance was considered. Therefore, we conducted our study to clarify the combined effects between side of dominance and 3-D kinematic motions.

The results of our study indicated that spinal ROM was significantly different based on region $\times$ dominance as well as between dominance $\times$ dimension. In addition, a three-way interaction was found between region, dominance, and dimension. Some variability was expected to exist between and within participants; however, a significant difference was found in rotational displacement of the transverse and sagittal axes, which significantly increased when the participants attempted to rotate, especially on the nondominant hip. In addition, a three-way interaction was found between body region, dimension, and age.

The combined effect of decreased axial trunk ROM on the dominant hip might stiffen passive structures of the hip joint because of increasing age. The functions of the lumbar spine and hip joints might be altered based on the stiffened side of dominance of the hip joint. This stiffened functional motion is important to examine for one to understand compensatory mechanisms in addition to poor proprioception in participants with LBP. Overall, this finding suggests that decreased ROM for the lumbar spine and both hips might limit the coordination of postural adjustability, especially on the dominant side [3233]. This uncoordinated axial rotation of the trunk might be a risk of spinal injuries during twisting activities.

Although we did not measure activities of electromyography during trunk rotation, a relationship between hip muscle activities that occur in response to lumbar stiffness could be investigated. To maintain postural stability during axial trunk rotation activities within a certain functional ROM, the body requires not only reliable sensory feedback or muscle activation from all involved joints but also the sensitive response of proprioceptive receptors. The efficacy of spinal coordination of kinematic analyses during axial trunk rotation could be affected by proprioceptive deficits as well as postural balance and neuromuscular performance [34-35]. The results of our study indicated that 3-D kinematic data of spinal ROM were significantly different for the dominant side as well as the lumbar spine. A three-way interaction was found between region, dominance, and dimension during axial trunk rotation regardless of age.

Spinal ROM might be affected by increased stiffness because of a repeated pattern of movements as Janda reported [36]. These results exemplify the need to investigate 
further the lumbar and hip regions based on 3-D analysis, while considering the dominance effect for trunk rotational displacement. Several studies provided a concept of regional interdependence and a detailed overview of the evidence supporting the potential interactions between the lumbar spine and hip joints [37-38]. The early detection of stiffened hip joints and overall spinal flexibility could be important in understanding compensatory mechanisms and preventing back injuries.

In addition, age was clinically relevant when we evaluated different compensatory responses during trunk movements [39-40]. Our results also support the decrease in transverse axis displacement, especially in older persons. In a recent review, impaired balance, poor muscle strength, visual impairment, impaired gait, and activities of daily living limitations have consistently been found to increase the risk of postural problems in older persons [41-42]. Therefore, one should understand the potential benefit of dominant hip joint flexibility strategies based on pathomechanical spinal movement patterns. During axial rotation, the ROM of the dominant hip joint might be limited; however, our study did not examine the cause and effect relationship. These motion patterns might be assumed to be functional compensation strategies following altered neuromuscular coordination, which might be the consequence of an imprecise internal estimate of compensation because of reduced accuracy in the sensory integration process.

One limitation of this study was the selection of the group, which included "volunteers." Increasing the number of participants would increase the power of the study. Another limitation was that the individual participants might vary even within a nondisabled population. The variability between the results of the dominant and nondominant lower limbs might not be significant since no significant change was found in the axial trunk rotation test. Quantifying inter- and intraparticipant variability with subgroup analyses would be beneficial, which can validate the test.

Despite these limitations, a number of populations, including nondisabled participants, value the quantification of dominant hip motion deficits. This study particularly interests the clinician who commonly evaluates the hip and lumbar spine and assesses patient progress in the rehabilitation setting. The lack of motion of the dominant hip joint in the transverse and sagittal axes might be related to the flexibility of the whole spinal region. A participant with a stiffened back might demonstrate decreased hip joint flexibility in addition to poor proprioception from back injuries to passive structures. Followup randomized, controlled trials are needed for investigating the characteristics of hip joint flexibility and adjustability as well as spinal compensation strategies for enhancing both biomechanical and neuromuscular aspects of age differences.

\section{CONCLUSIONS}

Our study demonstrated that spinal ROM was significantly different for the dominance, region, and hip motion. The results of a three-way interaction between region, dominance, and dimension indicated that a significant difference existed in the rotational displacement of the transverse and sagittal axes, which significantly increased when the participants attempted to rotate, especially on the dominant hip. Decreased axial trunk ROM on the dominant hip was related to stiffened passive structures of the hip joint. The functions of the hip joints and lumbar spine might be altered based on the stiffened dominant hip joint, although some variability exists between and within participants.

\section{ACKNOWLEDGMENTS}

\section{Author Contributions:}

Study concept and design: P. S. Sung, Y. H. Kim.

Acquisition of data: P. S. Sung.

Analysis and interpretation of data: P. S. Sung.

Drafting of manuscript: P. S. Sung.

Critical revision of manuscript for important intellectual content:

P. S. Sung.

Statistical analysis: P. S. Sung.

Obtained funding: Y. H. Kim.

Administrative, technical, or material support: Y. H. Kim.

Study supervision: P. S. Sung, Y. H. Kim.

Financial Disclosures: The authors have declared that no competing interests exist.

Funding/Support: This material was based on work supported by the National Agenda Project, funded by the Korea Research Council of Fundamental Science and Technology, grant P-09-JC-LU63-C01. This research was also partially supported by Korea University and the Basic Science Research Program through the National Research Foundation of Korea, funded by the Ministry of Education, Science and Technology, grant 2010-0003015.

Institutional Review: Study participants signed a copy of the institutional review board-approved consent form after they received information regarding the purpose and methods of the study. 
Participant Follow-Up: The authors do not plan to inform participants of the publication of this study. However, participants have been encouraged to check the study Web site for updated publications.

\section{REFERENCES}

1. Frymoyer JW, Cats-Baril WL. An overview of the incidences and costs of low back pain. Orthop Clin North Am. 1991;22(2):263-71. [PMID: 1826550]

2. Van Tulder M, Malmivaara A, Esmail R, Koes B. Exercise therapy for low back pain: A systematic review within the framework of the cochrane collaboration back review group. Spine (Phila Pa 1976). 2000;25(21):2784-96.

[PMID: 11064524]

DOI:10.1097/00007632-200011010-00011

3. Marras WS, Davis KG, Granata KP. Trunk muscle activities during asymmetric twisting motions. J Electromyogr Kinesiol. 1998;8(4):247-56. [PMID: 9779398$]$

DOI:10.1016/S1050-6411(98)00011-X

4. Dolan P, Adams MA. Influence of lumbar and hip mobility on the bending stresses acting on the lumbar spine. Clin Biomech. 1993;8(4):185-92.

DOI:10.1016/0268-0033(93)90013-8

5. Ellison JB, Rose SJ, Sahrmann SA. Patterns of hip rotation range of motion: A comparison between healthy subjects and patients with low back pain. Phys Ther. 1990;70(9): 537-41. [PMID: 2144050]

6. Fogel GR, Esses SI. Hip spine syndrome: Management of coexisting radiculopathy and arthritis of the lower extremity. Spine J. 2003;3(3):238-41. [PMID: 14589205] DOI:10.1016/S1529-9430(02)00453-9

7. Esola MA, McClure PW, Fitzgerald GK, Siegler S. Analysis of lumbar spine and hip motion during forward bending in subjects with and without a history of low back pain. Spine (Phila Pa 1976). 1996;21(1):71-78. [PMID: 9122766]

8. Hamaoui A, Do MC, Poupard L, Bouisset S. Does respiration perturb body balance more in chronic low back pain subjects than in healthy subjects? Clin Biomech (Bristol, Avon). 2002;17(7):548-50. [PMID: 12206948] DOI:10.1016/S0268-0033(02)00042-6

9. Hamaoui A, Do MC, Bouisset S. Postural sway increase in low back pain subjects is not related to reduced spine range of motion. Neurosci Lett. 2004;357(2):135-38.

[PMID: 15036593]

DOI:10.1016/j.neulet.2003.12.047

10. Pearcy M, Portek I, Shepherd J. The effect of low-back pain on lumbar spinal movements measured by threedimensional X-ray analysis. Spine (Phila Pa 1976). 1985; 10(2):150-53. [PMID: 3159103$]$
11. Burton AK. Regional lumbar sagittal mobility: Measurement by flexicurves. Clin Biomech (Bristol, Avon). 1986;1: 20-26. DOI:10.1016/0268-0033(86)90032-X

12. Hultman G, Saraste H, Ohlsen H. Anthropometry, spinal canal width, and flexibility of the spine and hamstring muscles in 45-55-year-old men with and without low back pain. J Spinal Disord. 1992;5(3):245-53. [PMID: 1387820] DOI:10.1097/00002517-199209000-00001

13. Troup JD, Foreman TK, Baxter CE, Brown D. 1987 Volvo award in clinical sciences. The perception of back pain and the role of psychophysical tests of lifting capacity. Spine (Phila Pa 1976). 1987;12(7):645-57. [PMID: 2961081] DOI:10.1097/00007632-198709000-00003

14. Lankhorst GJ, Van de Stadt RJ, Van der Korst JK. The natural history of idiopathic low back pain. A three-year followup study of spinal motion, pain and functional capacity. Scand J Rehabil Med. 1985;17(1):1-4. [PMID: 3159080]

15. Hodges PW, Richardson CA. Contraction of the abdominal muscles associated with movement of the lower limb. Phys Ther. 1997;77(2):132-44. [PMID: 9037214]

16. Sparto PJ, Parnianpour M, Reinsel TE, Simon S. The effect of fatigue on multijoint kinematics, coordination, and postural stability during a repetitive lifting test. J Orthop Sports Phys Ther. 1997;25(1):3-12. [PMID: 8979170]

17. Turner $\mathrm{CH}$. Effects of tissue viscoelasticity on mechanical loading models using rats. Bone. 1999;25(6):742.

[PMID: 10593421] DOI:10.1016/S8756-3282(99)00233-1

18. Wilder DG, Aleksiev AR, Magnusson ML, Pope MH, Spratt KF, Goel VK. Muscular response to sudden load. A tool to evaluate fatigue and rehabilitation. Spine (Phila Pa 1976). 1996;21(22):2628-39. [PMID: 9045348] DOI:10.1097/00007632-199611150-00013

19. Sung PS, Spratt KF, Wilder DG. A possible methodological flaw in comparing dominant and nondominant sided lumbar spine muscle responses without simultaneously considering hand dominance. Spine (Phila Pa 1976). 2004;29(17): 1914-22. [PMID: 15534417]

20. Marras WS, Parakkat J, Chany AM, Yang G, Burr D, Lavender SA. Spine loading as a function of lift frequency, exposure duration, and work experience. Clin Biomech (Bristol, Avon). 2006;21(4):345-52. [PMID: 16310299] DOI:10.1016/j.clinbiomech.2005.10.004

21. Marras WS, Rangarajulu SL, Lavender SA. Trunk loading and expectation. Ergonomics. 1987;30(3):551-62. DOI:10.1080/00140138708969744

22. Jo HJ, Song AY, Lee KJ, Lee DC, Kim YH, Sung PS. A kinematic analysis of relative stability of the lower extremities between subjects with and without chronic low back pain. Eur Spine J. 2011;20(8):1297-303. Epub 2011 Jan 20. [PMID: 21249507] 
23. Sung PS, Yoon B, Lee DC. Lumbar spine stability for subjects with and without low back pain during one-leg standing test. Spine (Phila Pa 1976). 2010;35(16):E753-60. [PMID: 20634657]

24. Lee RY, Wong TK. Relationship between the movements of the lumbar spine and hip. Hum Mov Sci. 2002;21(4): 481-94. [PMID: 12450680] DOI:10.1016/S0167-9457(02)00117-3

25. Pearcy MJ, Gill JM, Whittle MW, Johnson GR. Dynamic back movement measured using a three-dimensional television system. J Biomech. 1987;20(10):943-49.

[PMID: 3693375]

DOI:10.1016/0021-9290(87)90323-X

26. Brophy R, Silvers HJ, Gonzales T, Mandelbaum BR. Gender influences: The role of leg dominance in ACL injury among soccer players. Br J Sports Med. 2010;44(10):694-97. [PMID: 20542974]

DOI:10.1136/bjsm.2008.051243

27. Andersen TE, Floerenes TW, Arnason A, Bahr R. Video analysis of the mechanisms for ankle injuries in football. Am J Sports Med. 2004;32(1 Suppl):69S-79S. [PMID: 14754862] DOI:10.1177/0363546503262023

28. Portney LG, Watkins MP. Foundations of clinical research applications to practice. 3rd ed. Upper Saddle River (NJ): Pearson \& Prentice Hall; 2009.

29. Kantor E, Poupard L, Le Bozec S, Bouisset S. Does body stability depend on postural chain mobility or stability area? Neurosci Lett. 2001;308(2):128-32.

[PMID: 11457576] DOI:10.1016/S0304-3940(01)01986-3

30. Hodges PW, Gurfinkel VS, Brumagne S, Smith TC, Cordo PC. Coexistence of stability and mobility in postural control: Evidence from postural compensation for respiration. Exp Brain Res. 2002;144(3):293-302. [PMID: 12021811] DOI:10.1007/s00221-002-1040-X

31. Shum GL, Crosbie J, Lee RY. Movement coordination of the lumbar spine and hip during a picking up activity in low back pain subjects. Eur Spine J. 2007;16(6):749-58.

[PMID: 16715308]

DOI:10.1007/s00586-006-0122-z

32. Takala EP, Korhonen I, Viikari-Juntura E. Postural sway and stepping response among working population: Reproducibility, long-term stability, and associations with symptoms of the low back. Clin Biomech (Bristol, Avon). 1997; 12(7-8):429-37. [PMID: 11415752] DOI:10.1016/S0268-0033(97)00033-8

33. Imagama S, Matsuyama Y, Hasegawa Y, Sakai Y, Ito Z, Ishiguro N, Hamajima N. Back muscle strength and spinal mobility are predictors of quality of life in middle-aged and elderly males. Eur Spine J. 2011;20(6):954-61.

[PMID: 21072545]

DOI:10.1007/s00586-010-1606-4
34. Kuukkanen TM, Mälkiä EA. An experimental controlled study on postural sway and therapeutic exercise in subjects with low back pain. Clin Rehabil. 2000;14(2):192-202. [PMID: 10763797] DOI:10.1191/026921500667300454

35. Gill KP, Callaghan MJ. The measurement of lumbar proprioception in individuals with and without low back pain. Spine (Phila Pa 1976). 1998;23(3):371-77. [PMID: 9507628] DOI:10.1097/00007632-199802010-00017

36. Janda V. Differential diagnosis of muscle tone in respect of inhibitory techniques. J Man Med. 1989;4(3):96-99.

37. Reiman MP, Weisbach PC, Glynn PE. The hips influence on low back pain: A distal link to a proximal problem. J Sport Rehabil. 2009;18(1):24-32. [PMID: 19321904

38. Wainner RS, Whitman JM, Cleland JA, Flynn TW. Regional interdependence: A musculoskeletal examination model whose time has come. J Orthop Sports Phys Ther. 2007;37(11):658-60. [PMID: 18057674]

39. Dubost V, Beauchet O, Manckoundia P, Herrmann F, Mourey F. Decreased trunk angular displacement during sitting down: An early feature of aging. Phys Ther. 2005; 85(5):404-12. [PMID: 15842189]

40. Baer GD, Ashburn AM. Trunk movements in older subjects during sit-to-stand. Arch Phys Med Rehabil. 1995;76(9): 844-49. [PMID: 7668956] DOI:10.1016/S0003-9993(95)80550-8

41. Tinetti ME, Kumar C. The patient who falls: "It's always a trade-off.” JAMA. 2010;303(3):258-66. [PMID: 20085954] DOI:10.1001/jama.2009.2024

42. Delbaere K, Close JC, Heim J, Sachdev PS, Brodaty H, Slavin MJ, Kochan NA, Lord SR. A multifactorial approach to understanding fall risk in older people. J Am Geriatr Soc. 2010;58(9):1679-85. [PMID: 20863327] DOI:10.1111/j.1532-5415.2010.03017.x

Submitted for publication December 9, 2010. Accepted in revised form February 28, 2011.

This article and any supplementary material should be cited as follows:

Sung PS, Kim YH. Kinematic analysis of symmetric axial trunk rotation on dominant hip. J Rehabil Res Dev. 2011;48(8):1029-36.

DOI:10.1682/JRRD.2010.12.0232

ResearcherID: Paul S. Sung, PhD, DHSc, PT: E-5108-2011

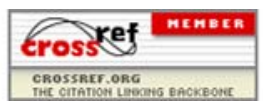

